\title{
Characterization of Catalytic Porous Medium Using Platinum for Micro-combustion Application
}

\author{
Muhamad Azman Miskam ${ }^{1, a}$, Suhaimi Hassan², Zainal Alimuddin Zainal Alauddin ${ }^{3}$ and Mohammad \\ Zulfikar Ishak ${ }^{3}$ \\ ${ }^{1}$ Science and Engineering Research Centre, Engineering Campus, Universiti Sains Malaysia, 14300 \\ Nibong Tebal, Pulau Pinang, Malaysia \\ ${ }^{2}$ Department of Mechanical Engineering, Universiti Teknologi PETRONAS, Bandar Seri Iskandar, \\ 31750 Tronoh, Perak, Malaysia \\ ${ }^{3}$ School of Mechanical Engineering, Engineering Campus, Universiti Sains Malaysia, 14300 Nibong \\ Tebal, Pulau Pinang, Malaysia
}

\begin{abstract}
In this study, catalytic alumina porous medium has been fabricated by using platinum as an active material for micro-combustion application. Platinum has been deposited onto porous medium surface via wet impregnation method. The porous medium undergoes surface modification process via wash coating method using gamma alumina $(\gamma$-Al2O3) solution, before being impregnated with platinum in order to increase the surface area. The surface morphology of porous medium entirely changes from smooth "solid-rock" into rough "sand-like" after the wash coating process. The amount of platinum deposited onto the treated porous medium is $1.66 \mathrm{wt} . \%$. LPG combustion analysis shows that the combustion is successfully occur inside the catalytic porous media with overall efficiency of $71 \%$.
\end{abstract}

\section{Introduction}

A porous medium or porous material can be defined as a medium that containing pores. It usually characterized by its porosity or pore structure and being used in many areas such as filtration, soilmechanics, material science, geo-mechanics and petrochemical field [1]. The utilization of porous medium in combustion significantly improves the combustion efficiency and produces very low unburned hydrocarbon, nitrogen oxides $\left(\mathrm{NO}_{\mathrm{x}}\right)$ and carbon monoxide $(\mathrm{CO})$ [2]. The productions of unburned hydrocarbon, $\mathrm{NO}_{\mathrm{x}}$ and $\mathrm{CO}$ in porous medium combustion are very low because of the high temperature exhaust gases has very high residence time in a postcombustion region which help to preheat the incoming fuel. Combustion in porous medium is slightly differ with the conventional homogeneous gas phase combustion because the porous medium provide very high surface area for combustion reaction which would results in very efficient heat transfer between the combustible reactants (air and fuel) and the inert solid. Porous medium increases the effective diffusion and heat transfer between the combustion phases during the dispersion of the reactant flowing through the porous medium [3].

\footnotetext{
${ }^{\text {a }}$ Corresponding author : azman@usm.my
}

This is an Open Access article distributed under the terms of the Creative Commons Attribution License 2.0, which permits unrestricted use, distribution, and reproduction in any medium, provided the original work is properly cited. 
The used of catalyst appears as one of the most attractive options for microscale combustion because of its capability to reduce the impact of thermal and radical quenching due to high heat loss to the surroundings as a result of the combustor high surface area to volume ratio [4]. Catalytic combustion can take place at significantly low temperature, easy start-up, low pollution gas emission, and capable to operate at a very lean air-to-fuel ratio condition $[5,6]$. Usually, noble metals such as platinum, palladium or rhodium with high porosity support are used as a catalyst in catalytic combustion. The presence of catalyst significantly increases the rate of combustion reaction by introducing much lower activation energy for the combustion reactants to react.

In this study, catalytic porous medium was developed and tested for microscale combustion application. Platinum is used as a catalyst and deposited onto the surface of porous medium (alumina) using wet impregnation method. The porous medium surface was modified using wash coating process with gamma alumina $(\gamma-\mathrm{Al} 2 \mathrm{O} 3)$ to increase the surface area. The surface morphology of the porous medium was examined via scanning electron microscopy (SEM), and the amount of deposited platinum was characterized via energy dispersive X-ray (EDX) spectroscopy. Finally, the performance of the developed catalytic porous medium was examined via liquefied petroleum gas (LPG)-air combustion.

\section{Catalytic porous medium microcombustor}

Figure 1 shows the schematic diagram of the developed catalytic porous medium microcombustor. The microcombustor is made from type-304 stainless steel which could withstand very high temperatures, rigid and very reliable. The microcombustor outer width, length and height are $30 \mathrm{~mm}$ respectively, similar to the HZ-2 thermoelectric cell surface area (Hi-Z technology) where in the future will be integrated to the microcombustor for electrical power generation [7]. The microcombustor has a pyramidal geometry entrance to induce uniform flow along and across the catalytic porous medium. The dimension of the catalytic porous medium section is $10 \mathrm{~mm} \times 10 \mathrm{~mm} \times$ $25.4 \mathrm{~mm}$ (length $\times$ width $\times$ thick). The porous medium was made from alumina, $\mathrm{Al}_{2} \mathrm{O}_{3}$ foam (Goodfellow Cambridge Limited) with pore size of $26 \mathrm{ppcm}$. The microcombustor's inlet has inner diameter of $1.6 \mathrm{~mm}$ and outer diameter of $3.2 \mathrm{~mm}$, respectively.

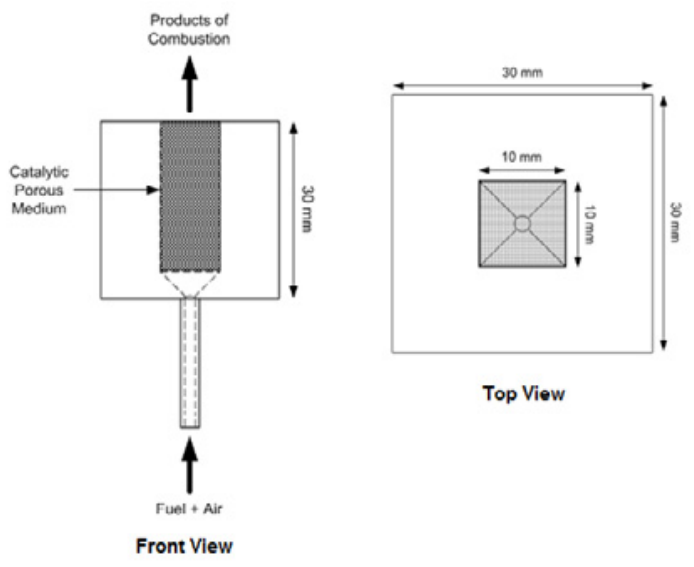

Figure 1. Schematic diagram of the catalytic porous medium microcombustor.

\section{Surface modification and platinum deposition}

The main objective for wash coating with $\gamma$-Al2O3 slurry is to roughen the porous medium surface to increase the surface area. Wash coating also used to protect the porous medium from corrosion by the strong chloroplatinic acid, $\mathrm{H}_{2} \mathrm{Cl}_{6} \mathrm{Pt}$ solution during the deposition of platinum. The surface 
modification process consists of two steps which are (1) surface cleaning process and (2) wash coating process. The cleaning process is done by washing the porous medium with acetone, $\left(\mathrm{CH}_{3}\right)_{2} \mathrm{CO}$ to ensure that the surface is free from any contaminant particles. The cleaning process is done by dipping the porous medium in acetone solution for 10 seconds per cycle and it was done with 5 cycles each. After that, the porous medium was dried in air at room temperature. The wash coating process is done by dipping the cleaned porous medium into slurry coating solution containing 5 wt. $\% \gamma$-alumina for two hours. The porous medium was then drawn out from the beaker, dried at $100{ }^{\circ} \mathrm{C}$ for 2 hours, and finally calcined at $500{ }^{\circ} \mathrm{C}$ in a furnace.

A wet impregnation method was performed to deposit platinum onto porous medium surface. This method was chosen because of its easy procedure yet can provide very good result. Firstly, the wash coated porous medium was placed in a container containing distilled water $(100 \mathrm{~mL}) .7 \mathrm{~mL}$ aqueous solution of $\mathrm{H}_{2} \mathrm{Cl}_{6} \mathrm{Pt}(0.007 \mathrm{M})$, was then slowly added to the container with continuous stirring on a magnetic stirrer. The solution $\mathrm{pH}$ was measured using a portable $\mathrm{pH}$ meter, and $1 \mathrm{M} \mathrm{NaOH}$ and $1 \mathrm{M}$ $\mathrm{HCl}$ were used to adjust the solution $\mathrm{pH}$ to 3 . After 2 hours the porous medium was drawn out from the container, dried and calcined at $500{ }^{\circ} \mathrm{C}$ in a furnace to reduce the $\mathrm{H}_{2} \mathrm{Cl}_{6} \mathrm{Pt}$ to platinum. The surface morphology of the porous medium before and after being deposited with platinum was examined using EDX spectroscopy.

\section{Results and Discussions}

\subsection{Characterization of porous medium with and without wash coating}

Figure 2 shows the surface morphology of the porous medium before and after surface modification process at magnification of $10,000 \times$. SEM characterization shows that the surface morphology of porous medium was obviously change before (Fig. 2a) and after (Fig. 2b) the surface modification process via wash coating with $\gamma$-alumina slurry solution. Initially, the porous medium has "solid-rock" morphology that is smooth and clean. After wash coating process, the morphology of porous medium entirely changes as it become "sand-like" that is very rough. The change in surface morphology significantly increases the expose surface area for the interaction with catalyst. The tendency of the catalyst to be deposited onto the rough surface is higher compared to the smooth surface morphology.
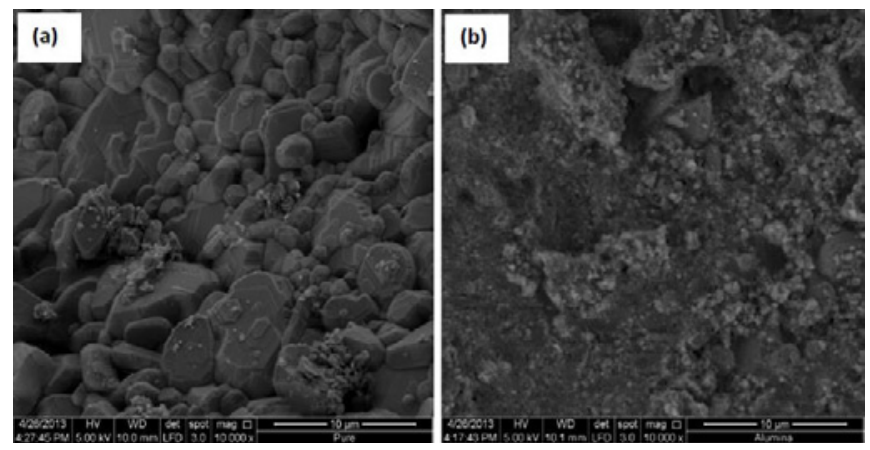

Figure 2. Porous medium surface morphology before (a) and after (b) wash coating treatment.

\subsection{Platinum deposition onto porous medium}

Figure 3 shows the SEM images of porous medium surface after deposited with platinum at magnification of $2,000 \times$ (a) and $10,000 \times$ (b). It was found that both deposition and dispersion of platinum onto porous medium surface are successfully achieved. It was proved by the existence of white precipitates at all over the porous medium surface. The platinum however is now well dispersed. This might be cause by the worn off $\gamma$-alumina coated during the preparation and deposition 
of platinum on the porous medium surface. Fig. 4 shows the results from EDX spectroscopy. The amount of deposited platinum onto porous medium surface is $1.66 \mathrm{wt} . \%$.

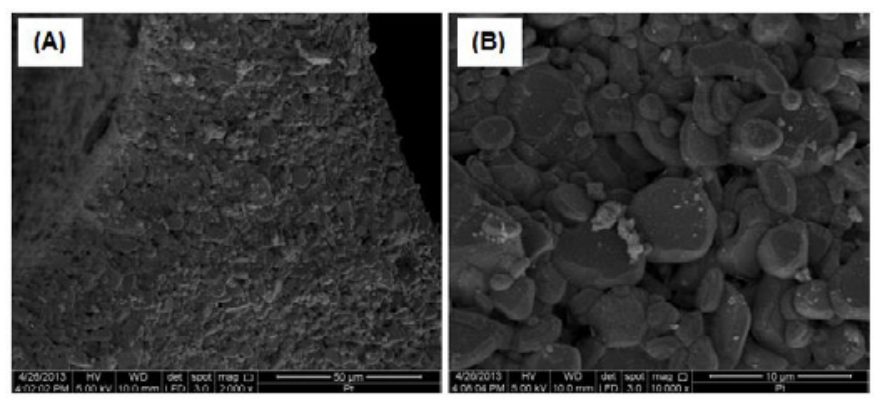

Figure 3. Porous medium surface morphology after deposited with platinum. (a) 2,000× magnification, (b) $10,000 \times$ magnification.

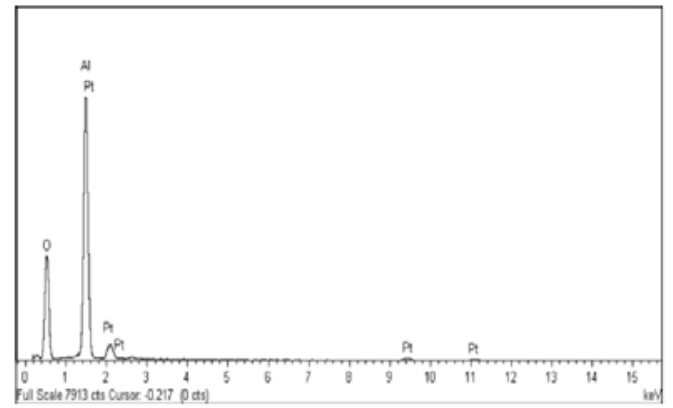

Figure 4. EDX analysis result.

\subsection{Combustion characteristics}

Fig. 5 shows the images of the flame produced from LPG $\left(40 \% \mathrm{C}_{3} \mathrm{H}_{8}, 60 \% \mathrm{C}_{4} \mathrm{H}_{10}\right)$ combustion at stoichiometric conditions for the catalytic (Fig. 5b) and un-catalytic microcombustor (Fig. 5a). The LPG flow rate is fixed at $0.1 \mathrm{slpm}$ during the experiment by using digital mass flow controller. For un-catalytic porous medium, a flame can be observed at the top of the porous medium. The opposite happens to catalytic porous medium because the combustion tends to occur inside the catalytic pores. Flue gas analysis shows efficiency of catalytic combustion is $71 \%$.

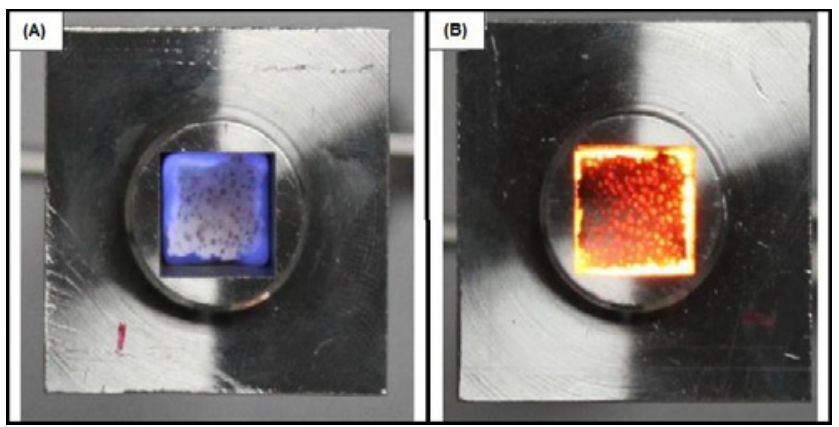

Figure 5. Flame shape for un-catalytic (a) and catalytic (b) porous medium. 
Fig. 6 shows the temperature distribution profile at the external wall of catalytic porous medium microcombustor. It can be shows that the temperature distribution is slightly uniform along the microcombustor wall. This is because; the heat produced from combustion was trapped by the porous medium's pores. Thus the heat loss through the exhaust was minimized. The heat was transferred to uniformly to the microcombustor wall through the porous medium. Uniform temperature distribution at the wall is important for thermoelectric cell to produce high electrical power.

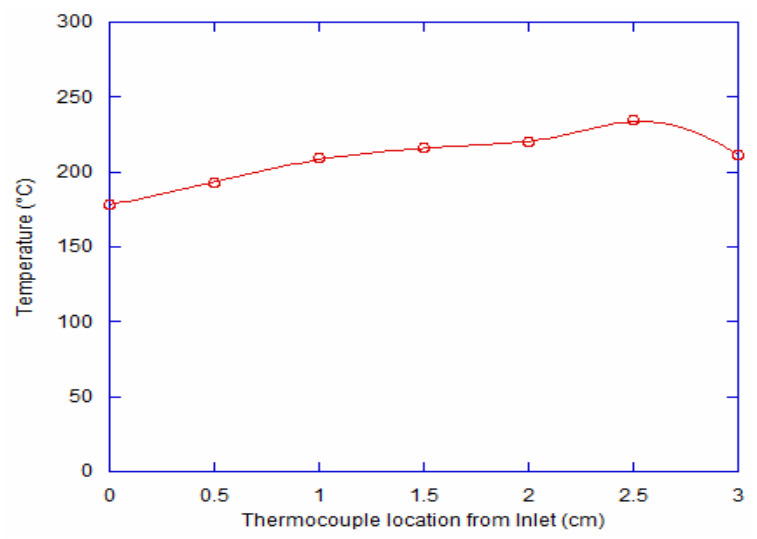

Figure 6. Temperature distribution profile at the microcombustor wall.

\section{Summary}

A catalytic porous medium was successfully developed by using wash coating process to increase the porous medium surface area and wet impregnation method to deposit platinum onto porous medium surface. The developed porous medium successfully makes the combustion reaction take place at the pores of the porous medium. The microcombusor also produce significantly uniform temperature profile which is very useful for the integration with thermoelectric cell for electrical power generation.

\section{Acknowledgement}

The authors gratefully acknowledge the financial support from Fundamental Research Grant Scheme Ministry of Higher Education Malaysia (203/PMEKANIK/6071228).

\section{References}

1. M.Y. Khan, A. Saxena, K.P. Singh, People's Journal of Science \& Technology, 2, 12-14 (2012).

2. M. Kaplan, M.J. Hall, Exp. Therm. Fluid Sci., 11, 13-20 (1995).

3. M.A. Mujeebu, M.Z. Abdullah, M.Z Abu Bakar, A.A. Mohamad, M.K. Abdullah, Appl. Energy, 86, 1365-1375 (2009).

4. Y. Wang, Z. Zhou, W. Yang, J. Zhou, J. Liu, Z. Wang and K. Cen, Energy Conv. Manag., 51, $1127-1133$ (2010).

5. D.G. Norton and D.G. Vlachos, Proc. Combust. Inst., 30, 2473-2480 (2005).

6. F. Moallemi, G. Batley, V. Dupont, T.J. Foster, M. Pourkashanian, A. Williams, Catal. Today, 47, 235-244 (199).

7. Information on http://www.hi-z.com 